\title{
Challenges Faced by Patients with Low Vision during COVID-19
}

\author{
Mantasha Dilkash $^{1}$, Susmita Banerjee ${ }^{2}$, Gaurav Dubey ${ }^{3 *}$, Vibha Kumari ${ }^{4}$, \\ Ragni Kumari ${ }^{5}$, Mahesh Chandra ${ }^{6}$, Himanshu Tripathi ${ }^{7}$, Yasmeen Shahid ${ }^{8}$ \\ ${ }^{1}$ PG, Master of Optometry Dr D. Y. Patil Institute of Optometry and Visual Sciences, Pune \\ ${ }^{2}$ Assistant Professor Dr D.Y.Patil Institute of Optometry and Visual Sciences Pune. \\ ${ }^{3}$ Faculty, Department of Optometry, Uttar Pradesh University of Medical Sciences, Saifai Etawah. \\ ${ }^{4}$ Assistant Professor Department of Paramedical Sciences, Jamia Hamdard, New Delhi. \\ ${ }^{5} \mathrm{PhD}$ Scholar Amity Institute of Public Health, Amity University, Noida \\ ${ }^{6}$ Sr. Optometrist, Department of Ophthalmology, Dr Sushila Tewari Hospital and Govt. Medical College, \\ Haldwani, Uttarakhand \\ ${ }^{7}$ Principal, Institute of Allied Health Sciences, Chandigarh University, Chandigarh \\ ${ }^{8} \mathrm{PG}$, Master of Optometry, Department of Optometry, TMU Moradabad.
}

Corresponding Author: Mr. Gaurav Dubey; Email Id-gauravopto25@gmail.com

\begin{abstract}
Purpose: Low vision patients have difficulties maintaining and keeping social distancing guidelines in the fight against the spread of the COVID-19 outbreak. This study examines COVID-19 and social distancing: Challenges faced by patients with low vision. The study objective is to identify the contribution of Covid-19 to the challenges faced by patients with low vision who visited the hospital. 35 low vision patients participated in the study.

Method: A self-administrated, cross-sectional survey in English was distributed using Google forms through various professional bodies across patients with low vision visiting the hospital. The questionnaire was also presented to the patients via telephonic conversation. The study objective is to identify the contribution of Covid-19 to the challenges faced by patients with low vision visited to the hospital and examine how social distancing measure has increased the challenges faced by patients with low vision. The questionnaire will contain closed-ended questions.

Result: Questionnaires were distributed to patients with low vision attending the hospital 35 responses were obtained through the questionnaire. Among the participants, 22 were males, and 19 were females. Patients who participated in the study were between 10 to 70 years of age. Social distancing increases the challenges faced by people with low vision. People with low vision had restrictive movement due to problems in maintaining social distancing and travelling outside. Challenges for low vision people depend upon the level of their sight loss; blind people rely on canes and a human guide. An individual with low vision can use their visual clues by identifying the shape and size of the object and their other senses to identify the object.

Conclusion: Coronavirus pandemic is a worldwide challenge that has spread across all sectors, including human. It applies to all industries. In no doubt, COVID-19 contributes to the faced by patients with low vision and the social distancing measures, which is one of the best ways of reducing the further spread of the disease across the globe.
\end{abstract}

Keywords- COVID-19, Challenges, Optometrist, Low Vision, Social Distancing

\section{INTRODUCTION}

Visual impairment is a significant concern everywhere in the world. According to the population-based examinations, mostly visually impaired individuals (more than 9 million) live in India in recent years. $^{[1,2]}$ 
The latest World Health Organization (WHO) measurements show that 285 million individuals are visually impaired worldwide, 39 million are blind, and 246 million have low vision. [9] According to WHO, visual impairment incorporates both low vision and visual impairment.

A person with low vision has impairment of visual function even after treatment and standard refractive correction and has a visual acuity of less than $6 / 18$ but equal to or better than $3 / 60$, or a visual field less than 20 degrees from the point of fixation in the better eye.

Low vision is a wide term utilized for conditions that decrease vision that can't be rectified even after all possible treatment. Low vision services function well to improve the quality of life and day-to-day living abilities of the person. The objective of any vision rehabilitation program is to empower low vision patients to live their life independently ${ }^{[3,4]}$

Worldwide, more than 6.5 million individuals are affected because of the COVID-19 and 387,155 deaths as of June 06, 2020; at the same time, 220,421 individuals are confirmed having COVID19 and 6348 deaths India. ${ }^{[5][6]}$ The COVID19 causes extreme intense respiratory disorder Covid 2 (SARS-CoV-2), which is transmitted through respiratory drops or direct contact with the contaminated surface or by hands, at that point of contact to mouth, nose, and eyes. The common symptoms of COVID-19 are fever, hack, and windedness with more uncommon manifestations like myalgia, loose bowels, and anosmia. ${ }^{[7][8]}$

Coronavirus has a great impact on the financial status, and this incorporates:

- Loss of talented and experienced laborer's.

- Reduced supply of labour.

- Loss of staff

- It causes poverty

- It reduces profitability and negative impact on financial development.
As a person with difficulties, the visually impaired rely on a sighted guide and cane to move securely, starting with one point and then onto the next, particularly in a crowded or unknown place. Social distancing makes various difficulties for the visually impaired, depending upon the level of visual impairment. The blind is dependent on their caning and auditory skills to adapt to the situation. Those with low vision can depend on their various objects to detect shapes and help them. ${ }^{[9]}$

As indicated by Royal National Institute for the Blind (2020), individuals attempting to get to the food have felt social distancing measures especially. The Director of Services of RNIB, David Clarke, announced that social distancing for the visually impaired is hard. Even though lockdown is removed, social distancing is still being implemented. People who are visually impaired are usually at a greater risk of getting the infection because of their way of life

This incorporates:

- Difficulty in maintaining cleanliness or finding the hand sanitizer that is available in the stores.

- Need to be guided by holding somebody's elbow, but elbows are currently utilized for sneezing and coughing)

- Need to use public transportation (United State Association of Blind Athletes, 2020). ${ }^{[9]}$

\section{METHODOLOGY}

A prospective cross-sectional survey was conducted within low vision patients visiting the hospital through a selfadministered questionnaire in English. Only patients with low vision visiting the hospital were included in the study. A selfadministrated questionnaire was distributed using Google forms through various professional bodies to patients with low vision visiting the hospital. The questionnaire was also presented to the patients via telephonic interview. Patients who participated in the study were between 
10 to 70 years of age. Patients with impairment of visual function even after treatment and standard refractive correction and visual acuity of less than $6 / 18$ but equal to or better than $3 / 60$, or a visual field less than 20 degrees from the point of fixation in the better eye were selected for the study. The study's objectives are to identify the contribution of Covid-19 to the challenges faced by patients with low vision visited the hospital and examine how social distancing measure has increased the challenges faced by patients with low vision. The questionnaire will contain closed-ended questions. (Annexure-1)

All participants were guaranteed anonymity and confidentiality of the information obtained. Approval was taken before the study from all patients with low vision participating in the study. Informed consent signed by all the subjects is included in the study. Subjects were informed about the research procedures, and the research is approved by the Institutional review board and the Ethics Committee for Human Research at Dr D.Y. Patil Vidyapeeth, Pune.

\section{INCLUSION CRITERIA}

$>$ Only patients with low vision visiting the hospital were included in the study.

$>$ Both male and Females.

\section{EXCLUSION CRITERIA}

$>$ Patients visiting the hospital other than low vision patients were not included in the study.

The survey included optometrists from hospitals, clinics, private sector, optical colleges, private sectors, etc. All the data was obtained through the survey; statistical analysis was done.

The result articulated through the survey was denoting in percentile format.

Annexure-1 (Questionnaire)

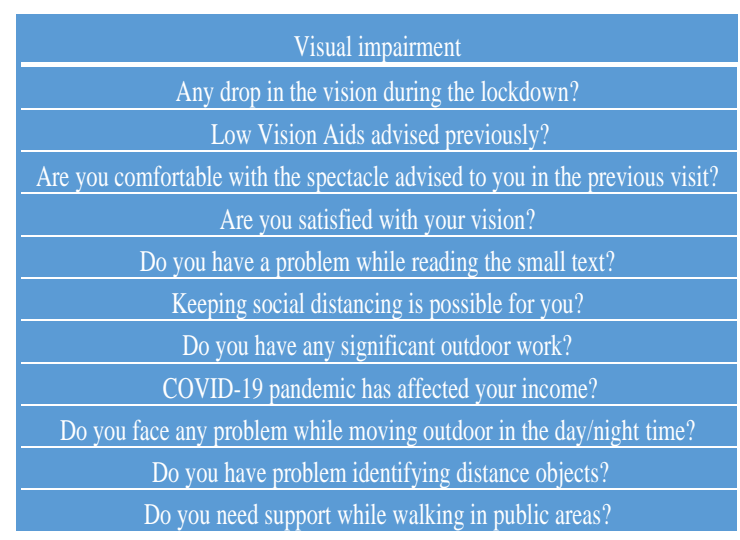

\section{RESULTS}

Questionnaires were distributed to patients with low vision attending the hospital. Consent was taken on telephonic interviews and before the extraction of data. 35 responses were obtained through the questionnaire. Among the participants, 22 were males, and 19 were females. Patients who participated in the study were between 10 to 70 years of age.(Table-1(a) (b))

Table-1(a) (b) Sociodemographic Variables $(n=35)$

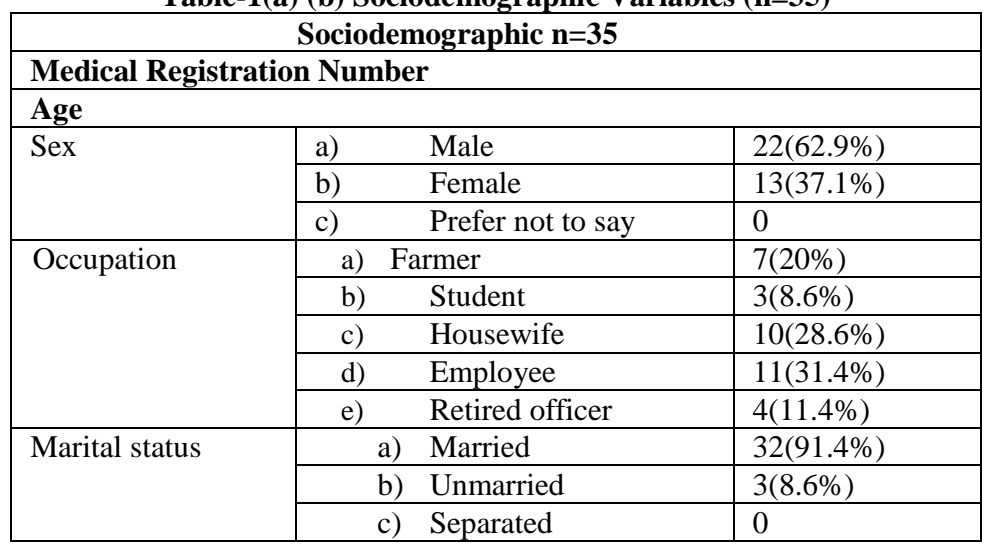


Mantasha Dilkash et.al. Challenges faced by patients with low vision during COVID-19.

Table-2 Questions- based on analysis among the studied population

\begin{tabular}{|c|c|c|c|}
\hline QUESTIONNAIRE & \multicolumn{3}{|c|}{ RESPONSE RATE } \\
\hline \multirow[t]{3}{*}{ 1. Visual impairment } & a) & Mild & $9(25.7 \%)$ \\
\hline & b) & Moderate & $5(14.3 \%)$ \\
\hline & c) & Severe/blind & $21(60 \%)$ \\
\hline \multirow[t]{2}{*}{ 2. Any drop in the vision during the lockdown? } & a) & Yes & $21(60 \%)$ \\
\hline & b) & No & $14(40 \%)$ \\
\hline \multirow[t]{2}{*}{ 3. Low Vision Aids advised previously? } & a) & Yes & 0 \\
\hline & b) & No & $35(100 \%)$ \\
\hline \multirow[t]{2}{*}{ 4. Are you comfortable with the spectacle advised to you in the previous visit? } & a) & Yes & $13(37.1 \%)$ \\
\hline & b) & No & $22(62.9 \%)$ \\
\hline \multirow[t]{2}{*}{ 5. Are you satisfied with your vision? } & a) & Yes & $3(8.6 \%)$ \\
\hline & b) & No & $32(91.4 \%)$ \\
\hline \multirow[t]{2}{*}{ 6. Do you have a problem while reading the small text? } & a) & Yes & $35(100 \%)$ \\
\hline & b) & No & 0 \\
\hline \multirow[t]{2}{*}{ 8. Do you have any significant outdoor work? } & a) & Yes & $25(71.4 \%)$ \\
\hline & b) & No & $10(28.6 \%)$ \\
\hline \multirow[t]{2}{*}{ 9. COVID-19 pandemic has affected your income? } & a) & Yes & $5(14.3 \%)$ \\
\hline & b) & No & $30(85.7 \%)$ \\
\hline \multirow[t]{2}{*}{ 10. Do you face any problems while moving outdoor in the day/nighttime? } & a) & Yes & $27(77.1 \%)$ \\
\hline & b) & No & $8(22.9 \%)$ \\
\hline \multirow[t]{2}{*}{ 11. Do you have a problem identifying distance objects? } & a) & Yes & $19(54.3 \%)$ \\
\hline & b) & No & $16(45.7 \%)$ \\
\hline \multirow[t]{2}{*}{ 12. Do you need support while walking in public areas? } & a) & Yes & $20(57.1 \%)$ \\
\hline & b) & No & $15(42.9 \%)$ \\
\hline
\end{tabular}

Table-1 (b) Sociodemographic Variables $(n=35)$

\begin{tabular}{|l|l|}
\hline AGE & Patients \\
\hline $\mathbf{1 0}$ to 20 & 3 \\
\hline $\mathbf{2 1}$ to 30 & 2 \\
\hline $\mathbf{3 1}$ to 40 & 4 \\
\hline $\mathbf{4 1}$ to 50 & 4 \\
\hline $\mathbf{5 1}$ to 60 & 7 \\
\hline $\mathbf{6 1}$ to 70 & 15 \\
\hline
\end{tabular}

\section{Sex}

F Female Male

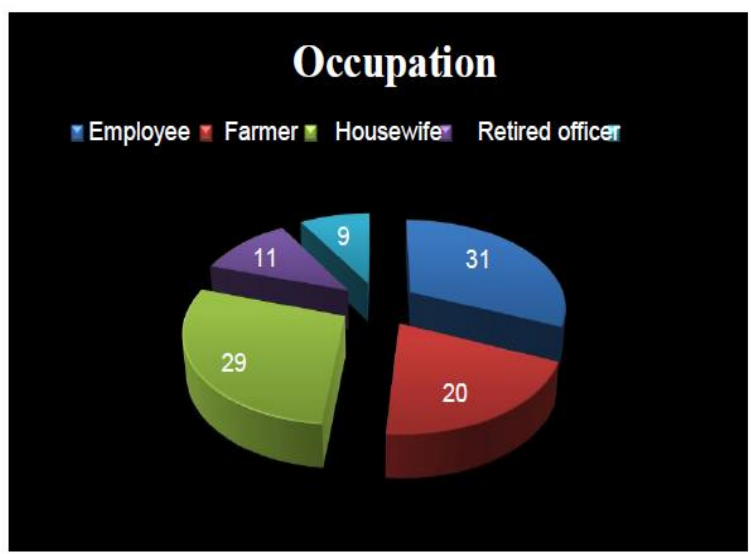

nemployee n Farmer $\mathbf{n}$ Housewifer Retired officer

[Graph: 1] Occupation of the Participants

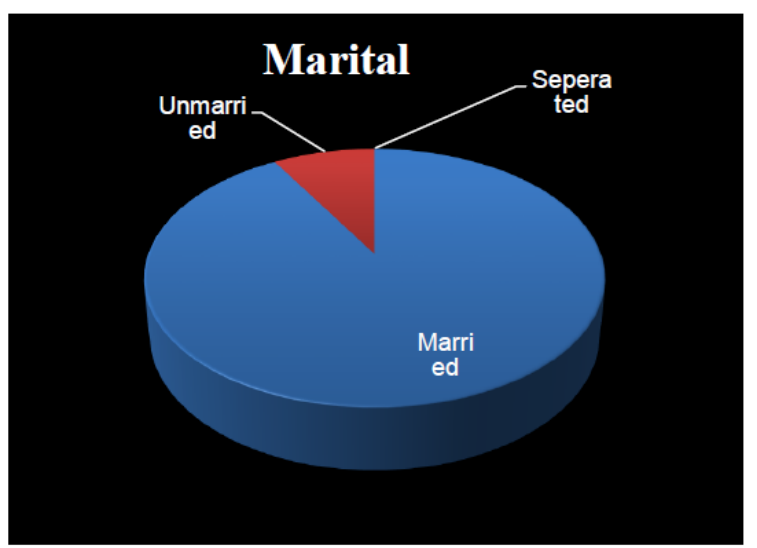

[Graph: 2] Marital Status of the Participants
1. Visual impairment

35 responses

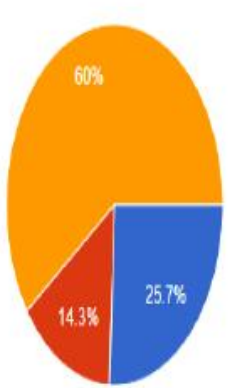

[Graph: 3] 
The occupation and marital status of the patients who participated are given in graphs 1 and 2, respectively.

Patient's subjective responses were taken in the questionnaire for the study.

In this study, $60 \%$ of patients stated themselves as severe visual impaired, $14.3 \%$ said they were moderate visual impaired, and $25.7 \%$ stated themselves as mild visual impaired. [Graph: 3]

\section{Any drop in the vision during the lockdown?}

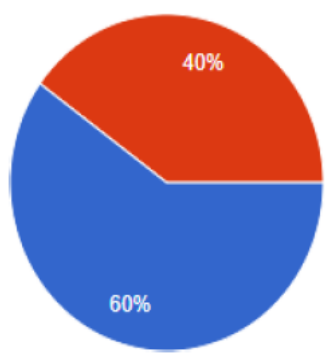

\section{Yes No}

[Graph: 4]

$60 \%$ of patients felt the drop in vision during lockdown due to COVID-19. Whereas $40 \%$ felt there was no drop in vision during the lockdown. [Graph: 4] None of them was advised with low vision aids [Graph: 5]. The patient gave no specific reasons for the sudden drop in vision as the patients were not going through proper follow up with their eye care practitioners during COVID 19.

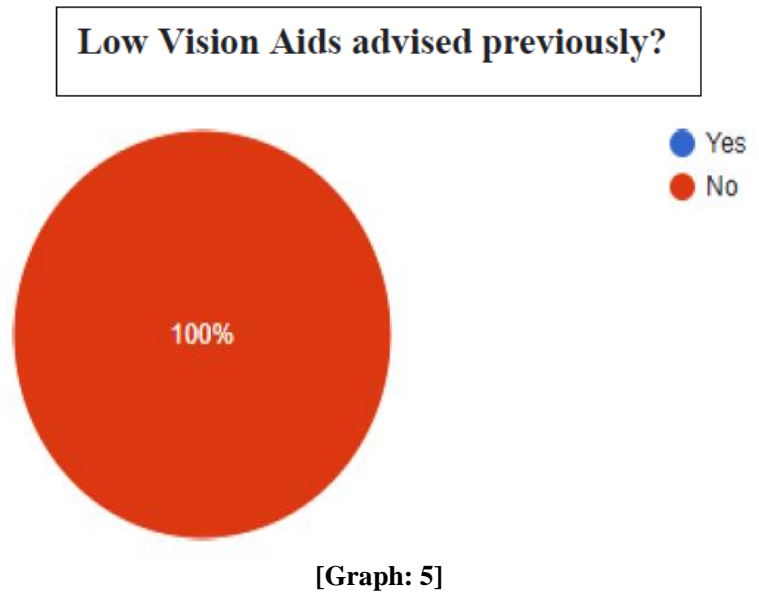

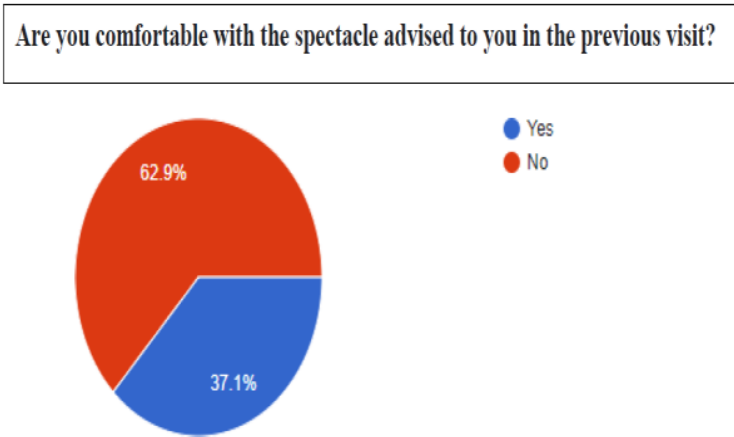

[Graph: 6]

Are you satisfied with your vision?

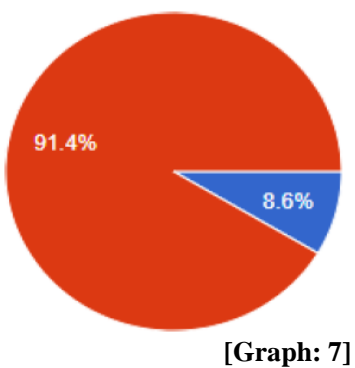

$62.9 \%$ of patients were not comfortable with the spectacle they advised in the previous visit, and $91.4 \%$ were not satisfied with their vision. [Graph: 6] [Graph: 7]

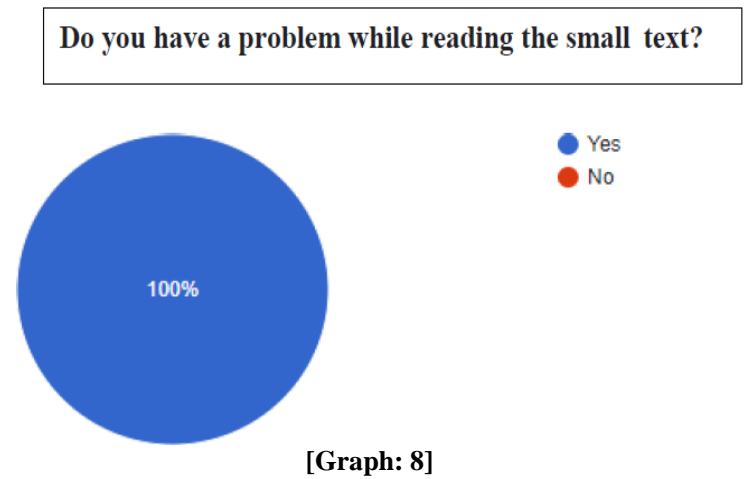

Do you have problem in identifying distance objects?

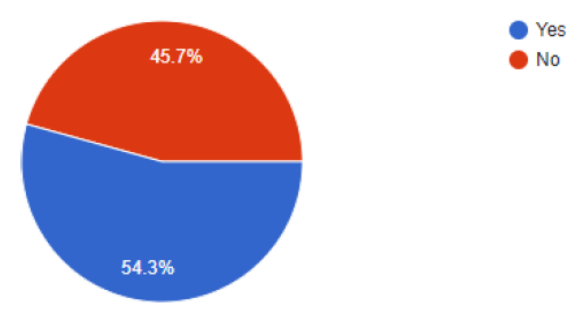

[Graph: 9] 
$100 \%$ of the patients had difficulty reading small text, and $54.3 \%$ of the patients stated that they have a problem identifying distant objects. [Graph: 8] [Graph: 9]

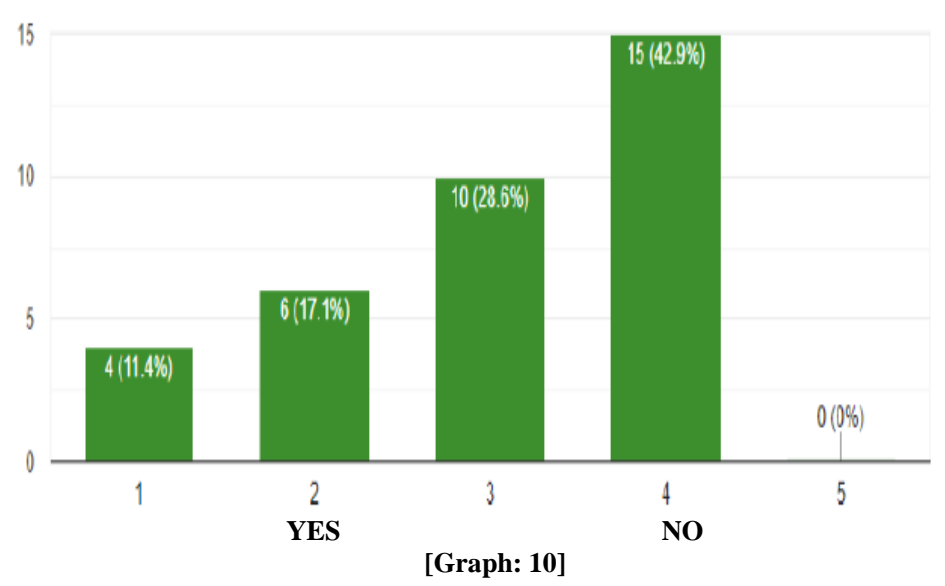

$42.9 \%$ of patients faced problems in maintaining social distancing. Whereas only $11.4 \%$ to $17.1 \%$ were comfortable maintaining social distancing. [Graph: 10]

Hence, Social distancing measure increases the challenges faced by persons with low vision. Most of them were unable to follow social distancing and travel outside due to visual impairment.

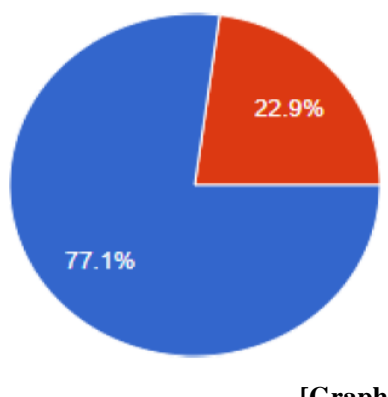

[Graph: 12]
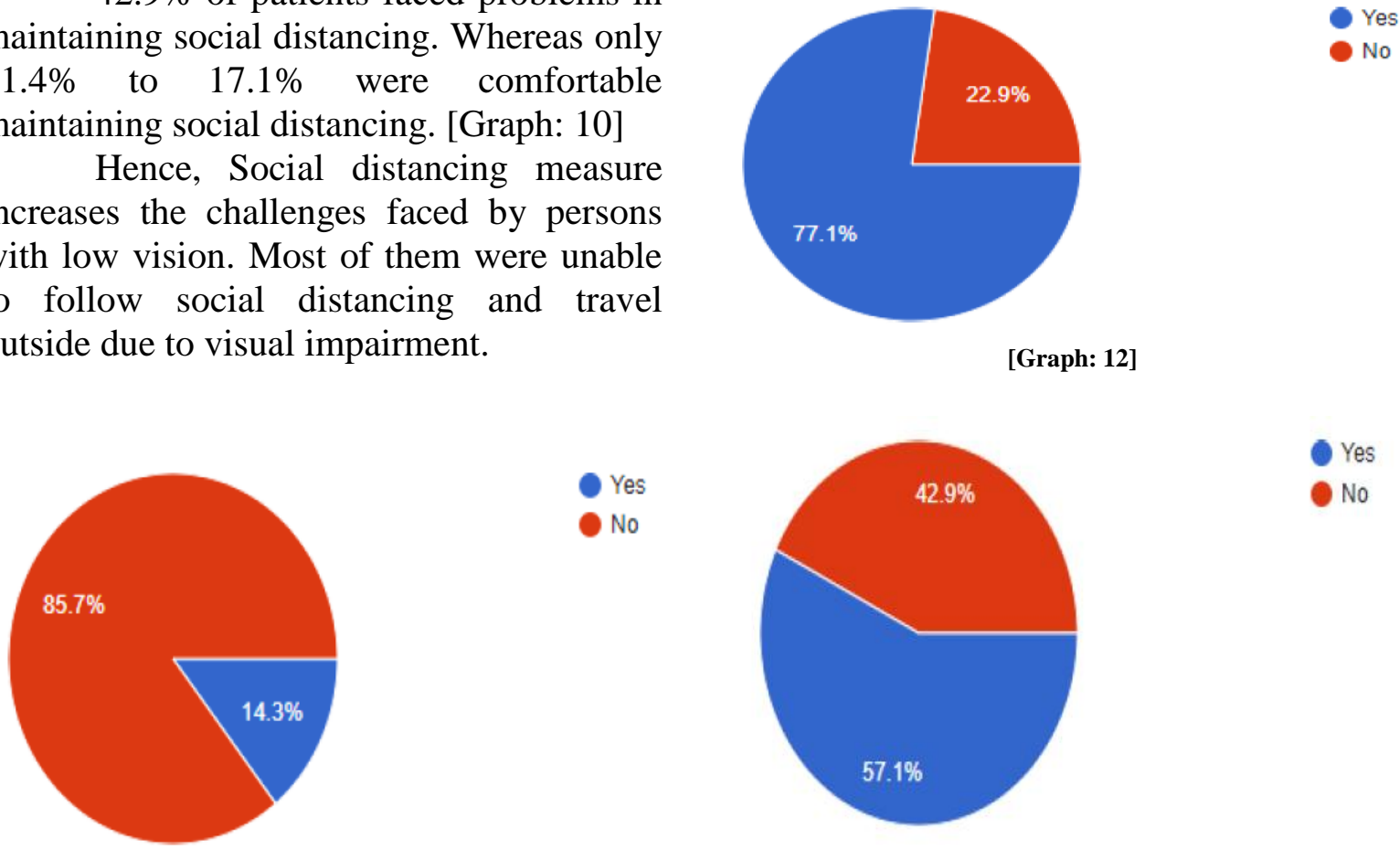

[Graph: 11]

[Graph: 13]

$85.7 \%$ of patients stated that there was no effect on income during the COVID19 pandemic. Whereas $14.3 \%$ of patients said that there was the effect on income during the COVID-19 pandemic [Graph: 11]

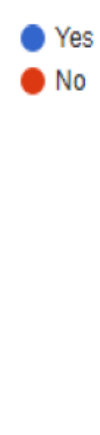


faced by patients with low vision. This was upheld with the perspective of Abodunrin, Oloye, and Adesola (2020), who detailed that, throughout the years, every country of the world is faced pandemics. Yet, the latest of all that is affecting the world is COVID19. Since the discovery of Covid in China, many cases came across outside China than inside, denoting another achievement in the spread of the worldwide pandemic. The infection has spread from China to the remaining world, prompting the World Health Organization to name the COVID-19 as a pandemic. Human-to-human transmissions got obvious after cases were recorded with no evidence connected to China. People with visual impairment are more likely to contract Coronavirus 2 (SARS- CoV 2) than individuals without visual impairment. The current pandemic, followed by lockdown to slow the spread of the virus, will truly affect individuals living with visual impairment. Many restrictive and control measures, including adopting new behavioural changes (for example, social distance during outdoor movement, limiting touch or tactile contact) recommended by the government, will pose immense challenges to individuals with a visual loss. This serious impact, including challenges in healthcare accessibility, can be minimized through inclusive service approaches, involving people with visual impairment, family members, healthcare providers, and the community to a large extent, and finally, support to improve the overall outcomes.

\section{CONCLUSION}

Coronavirus pandemic is a worldwide challenge that has spread across all sectors, including humans. It applies to all sectors. In no doubt, COVID-19 contributes to the faced by patients with low vision and social distancing measures, which is one of the best ways of reducing the further spread of the disease across the globe. Coronavirus effect on the global economy cannot be neglected. Government should ensure that everyone is appropriately following the guidelines for control of covid 19.

Social distancing increases the challenges faced by people with low vision. People with low vision had restrictive movement due to problems in maintaining social distancing and travelling outside. Challenges for low vision people depend upon the level of their sight loss; blind people rely on canes and a human guide. An individual with low vision can use their visual clues by identifying the shape and size of the object and their other senses to identify the object.

\section{Recommendations for patients:}

$>$ Persons with low vision should follow the Center for Disease Control rules in preventing COVID-19 like washing of hands routinely with cleanser and water, trying to touch eyes, nose, and mouth with unwashed hands, covering of mouth and nose with a tissue when coughing or sneezing, the practice of social distancing by avoiding going to crowded places.

$>$ Persons with low vision should be urged to remain at home, particularly if thoroughly dependent on a sighted guide if they are going to an unknown place

\section{Acknowledgement: None}

\section{Conflict of Interest: None}

\section{Source of Funding: None}

\section{Ethical Approval: Approved}

\section{REFERENCES}

1. Resnikoff S, Pascolini D, Etya'ale D, Kocur I, Pararajasegaram R, Pokharel GP, et al. Global data on visual impairment in the year 2002. Bull World Health Organ. 2004;82: 844-51.

2. Murthy GV, Gupta S, Ellwein LB, Munoz SR, Bachani D, Dada VK. A populationbased eye survey of older adults in a rural district of Rajasthan: I-Central vision impairment, blindness, and cataract surgery. Ophthalmology. 2001;108:679-85. 
3. Lamoureux EL, Pallant JF, Pesudovs K, Rees G, Hassell JB, Keeffe JE. The effectiveness of low-vision rehabilitation on participation in daily living and quality of life. Invest Ophthalmol Vis Sci. 2007;48: 1476-82.

4. Overbury O, Wittich W. Barriers to low vision rehabilitation: The Montreal Barriers study. Invest Ophthalmol Vis Sci. 2011; 52:8933-8.

5. The Government of India Fights Corona COVID-19 in India, Corona Virus Tracker | mygov.in. [Last accessed on 2020 June 06]

6. Ministry of Health \& Family Welfare Government of India. COVID 19 India. Available from: https://www.mohfw.gov.in/. [Last accessed on 2020 June 06]

7. Zhai P, Ding Y, Wu X, Long J, Zhong Y, Li Y. The epidemiology, diagnosis and treatment of COVID-19. Int J Antimicrob Agents 2020:105955. doi: 10.1016/j.ijantimicag. 2020.105955

8. Harapan $\mathrm{H}$, Itoh $\mathrm{N}$, Yufika A, Winardi W, Keam S, Te H, et al. (COVID19)Coronavirus disease 2019 A literature review. J. Infect. Public Health 2020;13:667-73

9. Sunday Abimbola Abodunrin, Oyinlola Abodunrin. COVID-19 And Social Distancing: Challenges Faced By Persons With Visual Impairment In South-West, Nigeria. GOJAMSS Journal. Vol.19, March 2020; P.107 -113 (ISSN: 2276 - 9013)

10. Abodunrin, O., Oloye, G. \& Adesola, B. (2020) Coronavirus Pandemic and Its Implication on Global Economy. International Journal of Arts, Languages and Business Studies (4) 13 - 23

11. Cohen, H. (2020) Why social distancing is a challenge for the blind and what can be done about it. Miami Herald, April 29. Corn, A. L, \& Lusk, K. E.(2010) Perspectives on low vision. In:
12. Kavitha, V, Manumali, M. S, Praveen K, \& Heralgi M. (2015) Low vision aid:- A ray of hope for irreversible visual loss in the pediatric age group. Taiwan J Ophthalmol. 2015;5(2):63-67. https://doi.org/10.1016/j.tjo

13. Royal National Institute for the Blind (2020) Social Distancing having a devastating effect on blind and partially sighted people $\mathrm{s}$ independence. Retrieved from https:

14. //www.rnib.org.uk/campaigning/campaignin g-news/social-distancing-havingdevastating- effecton-independence

15. United State Association of Blind Athletes (2020) COVID-19: Risks and Challenges for the visually impaired. Retrieved from https://www.usaba.org/covid-19-risks-andchallenges-for-the-visually-impaired

16. Dandona R, Dandona L, Srinivas M, Giridhar P, Nutheti R, Rao GN. Planning low vision services in India: A populationbased perspective. Ophthalmology. 2002; 109: 1871-8.

17. Overbury O, Wittich W. Barriers to low vision rehabilitation: The Montreal Barriers study. Invest Ophthalmol Vis Sci. 2011;52: 8933-8.

18. The World Health Organization. Coronavirus disease 2019. Available from:

https://www.who.int/emergencies/diseases/n ovel-coronavirus-2019. [Last accessed on 2020 June 06]

19. Senjam, Suraj S Impact of COVID-19 pandemic on people living with visual disability, Indian Journal of Ophthalmology: July 2020 - Volume 68 - Issue 7 - p 13671370. doi: 10.4103/ijo.IJO_1513_20

How to cite this article: Dilkash M, Banerjee S, Dubey $G$ et.al. Challenges faced by patients with low vision during COVID-19. Int $J$ Health Sci Res. 2021; 11(9): 67-74. DOI: https://doi. org/10.52403/ijhsr.20210910 